\title{
Percepções dos familiares de estudantes público-alvo da Educação Especial sobre o Atendimento Educacional Especializado
}

\author{
Perceptions of Family members of Studentes targeting Special Education \\ targeting Specialized Education Assistance \\ Percepciones de los familiares de estudiantes público objetivo de la \\ Educación Especial sobre el Servicio Educativo Especializado
}

\author{
Samuel Vinente da Silva Junior \\ Doutorando na Universidade Federal de São Carlos, São Carlos, SP, Brasil \\ E-mail: samueljunior.ns@gmail.com ORCID: https://orcid.org/0000-0002-7205-9680 \\ Fabiana Cia \\ Professora doutora da Universidade Federal de São Carlos, São Carlos, SP, Brasil \\ E-mail: fabianacia@hotmail.com ORCID: https://orcid.org/0000-0002-0155-3331
}

Recebido em 30 de julho de 2019

Aprovado em 12 de maio de 2021

Publicado em 21 de junho de 2021

\section{RESUMO}

A atual política de Educação Especial na perspectiva da Educação Inclusiva aponta como objetivo o acesso, a participação e a aprendizagem de estudantes público-alvo da Educação Especial (PAEE), devendo os sistemas de ensino garantir a participação da família e da comunidade. Essa interação é necessária para a efetivação do processo de inclusão escolar e o protagonismo da família na avaliação dos serviços especializados ofertados ao alunado. Dessa forma, o estudo objetivou descrever e analisar as percepções dos familiares de estudantes PAEE sobre o serviço de Atendimento Educacional Especializado (AEE) ofertado em um município amazonense de grande porte. Trata-se de uma pesquisa descritiva, desenvolvida por meio de abordagem qualitativa. Participaram um pai e quatro mães de estudantes PAEE, com idades entre 30 e 36 anos. Foi aplicado um roteiro semiestruturado de entrevista em uma escola da rede pública de ensino, localizada na zona norte do município. Os dados foram gravados, transcritos e analisados por meio de elaboração de categorias temáticas, com apreciação de três juízes para a garantia da fidedignidade. Os dados trouxeram indicadores favoráveis no tocante à avaliação e implementação do serviço de AEE a partir da perspectiva dos pais. Os participantes consideraram boa a atuação das professoras da sala de recursos multifuncionais e problematizam aspectos relacionados ao espaço da sala. Os resultados apontam para a necessidade de revisão dos serviços especializados, bem como a análise e a reformulação da atual Política de Educação Especial na Perspectiva da Educação Inclusiva.

Palavras-chave: Educação Especial; Família; Atendimento Educacional Especializado. 
http://dx.doi.org/10.5902/1984686X39311

\section{ABSTRACT}

The current Special Education policy from the perspective of inclusive Education points out as objective the acess to participation and the learning of students targeting Special Education (PAEE), Education systems must guarantee the participation of the Family and the community. This interaction is necessary to make the school inclusion process effective and the role of the family in the evaluation of specialized services offered to students. Thus, the study aimed to describe and analyze the perceptions of students family members PAEE about the Specialized Education Assistance service (AEE) offered in a large Amazonian municipality. It is a descriptive research developed through a qualitative approach. A father and four mothers of students participated PAEE, aged between 30 and 36 years. A semi-structured interview script was applied at a public school,located in the northern part of the municipality. The data were recorded transcrible and analyzed by elaboration thematic categories, with the appreciation of three judges for the guarantee of reliability. The data brought favorable indicators regarding the parents'perspective. The participants considered the performance of the classroom teachers to be good multifunctional resources and problematize aspects related to the specialized services, as well as the analysis and reformulation of the current Special Education policy from the perspective of inclusive Education.

Keywords: Special education; Family; Specialized Education Service.

\section{RESUMEN}

La política de Educación Especial en la perspectiva de la Educación Inclusiva apunta como objetivo el acceso, la participación y el aprendizaje de estudiantes público objetivo de la Educación Especial. Para ello los sistemas de enseñanza deben garantizar la participación de la familia y la comunidad. Considerando la relevancia de la participación de la familia para la efectividad del proceso de inclusión escolar y el protagonismo de éstos en la evaluación de los servicios especializados ofrecidos a los estudiantes público objetivo de la Educación Especial (PAEE), el estudio objetivó describir y analizar las percepciones de los familiares de estudiantes PAEE sobre el servicio de Atención Educativa Especializada ofrecido en un municipio amazonense de gran porte. Se trata de una investigación descriptiva, desarrollada por medio de un abordaje cualitativo. En el caso de los estudiantes de la Universidad de Buenos Aires, en la Universidad de Buenos Aires, Como procedimientos de recolección se aplicaron guías semiestructurados de entrevista en una escuela de la red pública de enseñanza ubicada en la zona centro-oeste de un municipio amazonense de gran porte. Los datos fueron analizados por medio de la elaboración de categorías temáticas, con la apreciación de tres jueces para la garantía de la fidedignidad del análisis realizado. Se espera que el estudio permita traer indicadores en cuanto a la evaluación e implementación del servicio de Atención Educativa Especializada desde la perspectiva de los padres, para contribuir en el análisis y reformulación de la política de inclusión escolar.

Palabras clave: Educación Especial; la familia; Atención al cliente. 
http://dx.doi.org/10.5902/1984686X39311

\section{Introdução}

\section{Política de Educação Especial e Atendimento Educacional Especializado}

No campo da educação especial, inúmeros avanços podem ser notados, principalmente no âmbito jurídico. O direito educacional dos estudantes público-alvo da Educação Especial (PAEE) é consignado na Carta Magna do Estado (BRASIL, 1988), no Estatuto da Criança e do Adolescente (BRASIL, 1990), na Lei de Diretrizes e Bases da Educação Nacional (BRASIL, 1996), no Decreto no 7.611/2011 (BRASIL, 2011), no Plano Nacional de Educação (BRASIL, 2014a) e no Estatuto da Pessoa com Deficiência (BRASIL, 2015).

A atual Política Nacional de Educação Especial na Perspectiva da Educação Inclusiva (PNEEP/EI) apresentou como objetivo o acesso, a participação e a aprendizagem dos estudantes PAEE no sistema regular de ensino. Dessa maneira, os sistemas devem potencializar a oferta do Atendimento Educacional Especializado (AEE) e a participação da família e da comunidade no processo de escolarização desses estudantes (BRASIL, 2008).

$O A E E$ foi definido na legislação nacional como um conjunto de atividades, recursos pedagógicos e de acessibilidade organizados de forma institucional e contínua. Para os estudantes com deficiência e transtornos globais do desenvolvimento, esse atendimento deve ser ofertado de forma complementar. Já para os estudantes com altas habilidades ou superdotação, a forma de atendimento é a suplementar (BRASIL, 2011).

Essas modalidades (complementar e suplementar) de atendimento foram discutidas por Haas (2016), apontando o caráter técnico e instrumental de oferta dos serviços especializados. Assim sendo, é preciso discutir também os sentidos que essa terminologia vem ganhando ao longo do tempo nas políticas públicas de Educação Especial em ação nos diferentes contextos, bem como no âmbito das Salas de Recursos Multifuncionais (SRM).

As SRM foram definidas na Portaria Normativa oㅜ 13/2007 como "[...] um espaço organizado com equipamentos de informática, ajudas técnicas, materiais pedagógicos e mobiliários adaptados, para atender às necessidades educacionais especiais dos alunos" (BRASIL, 2007, Art. 1ํ). Segundo Mendes e Cia (2012) tem-se privilegiado a oferta do AEE nessas salas, implantadas nos últimos anos por meio do Programa de Ações Articuladas (PAR), no âmbito do Ministério da Educação (MEC). 
http://dx.doi.org/10.5902/1984686X39311

Temos observado na literatura diversos estudos que analisam a oferta do AEE nessas salas, trabalhos esses desenvolvidos em diversas regiões do Brasil (BAPTISTA, 2011; MILANESI, 2012; ALMEIDA, 2013; NOZU, 2013; ALBUQUERQUE, 2015; VINENTE, 2017). Entretanto, essas pesquisas ao analisarem principalmente os aspectos sobre a formação de professores, a avaliação do alunado e o funcionamento das SRM, pouco discutem sobre a participação da família e as percepções das mesmas sobre os serviços especializados ofertados.

Pode-se considerar então que a PNEEP/El ao inserir também a participação da família e da comunidade como parte dos objetivos de tal política precisa contemplar aspectos dessa participação na formulação e implementação de políticas educacionais para essa população, bem como a avaliação e o monitoramento de sua implementação.

Assim sendo, pode-se observar no âmbito das políticas educacionais que a participação da família é um elemento pertinente para a efetivação do processo de inclusão escolar desses estudantes nos diferentes sistemas de ensino (BRASIL, 2008, 2011, 2014a).

Nessa mesma perspectiva, Maturana e Cia (2015) apontam que um dos principais fatores facilitadores no processo de inclusão escolar é a participação da família, ou seja, o relacionamento família-escola, diretamente vinculado ao sucesso escolar de estudantes público-alvo da Educação Especial.

Dessa maneira, o envolvimento dos pais com a escola não beneficia apenas as crianças, pois as instituições que encorajam os familiares a participarem dos assuntos da escolarização de seus filhos tendem a fortalecer a comunidade como um todo (MARINS; CIA, 2019).

\section{Atendimento Educacional Especializado e família de estudantes público-alvo da Educação Especial}

Conceitualmente, a família trata-se, então, de uma organização social, na qual o homem introduz-se desde que ingressa no mundo. A família seria então um conceito permanentemente novo, transformando e remodelando-se de acordo com os contornos da sociedade (BOARINI, 2003).

Corroborando Boarini (2003), Oliveira (2009) também aborda as transformações sociais, políticas e econômicas que dinamizam uma nova configuração familiar. Segundo Oliveira (2009), a concepção de família que historicamente foi sendo construída é fruto 
http://dx.doi.org/10.5902/1984686X39311

da trajetória de sua existência na sociedade, passando por profundas transformações e demonstrando o seu caráter dinâmico.

Considerando então parte dessas mudanças estruturais, a legislação brasileira assegura em sua Carta Magna a proteção à família, à maternidade, à infância, à adolescência e à velhice, bem como o amparo às crianças e aos adolescentes carentes (BRASIL, 1988).

No que se refere ao direito educacional, a Constituição Federal endossa que a educação é direito de todos e dever do Estado e da família, devendo ser promovida e incentivada com a colaboração da sociedade, visando ao pleno desenvolvimento da pessoa, seu preparo para o exercício da cidadania e sua qualificação para o trabalho (BRASIL, 1988).

Silveira (2010) também ressalta que o processo educacional não se dá de forma individual, mas de maneira coletiva. Nesse contexto, a educação compreende também a dimensão social, pois a formação de cada cidadão contribui para o desenvolvimento econômico, político e social de toda a sociedade. Assim, a educação é um dos requisitos imprescindíveis para o acesso ao conjunto de bens e serviços disponíveis na sociedade.

$\mathrm{Na}$ legislação educacional brasileira é possível observar uma série de direitos que garantem a escolarização de estudantes PAEE nos sistemas de ensino (BRASIL, 1990, 1996, 2015). No entanto, mesmo com vários mecanismos legais, efetivá-los é algo complexo.

É no sentido de efetivar o direito à educação, que a mesma é vista na ótica da legislação como um direito público e subjetivo (BRASIL, 1988). Tal direito confere ao indivíduo a possibilidade de transformar a norma geral e abstrata contida no ordenamento jurídico em algo próprio. Faz-se isso acionando as normas jurídicas (direito objetivo) e transformando-as em seu direito (direito subjetivo) (DUARTE, 2004).

Ao considerarmos então a necessidade de apropriação dos direitos sociais, tal como a educação, pelos familiares de pessoas com deficiência, estudos apontam que é imprescindível que as famílias se apropriem desses documentos e se empoderem para a busca da efetivação desses direitos (BRAVO; HAYASHI, 2010; ARAÚJO, 2011; BAQUERO, 2012; SMEHA; OLIVEIRA, 2014; VINENTE; DUARTE, 2017).

Tendo em vista a importância do empoderamento familiar para o fortalecimento dos serviços de Educação Especial, Gualda, Borges e Cia (2013) investigaram os recursos e as necessidades dos pais de crianças pré-escolares PAEE. Participaram do estudo doze 
http://dx.doi.org/10.5902/1984686X39311

pais de diferentes níveis socioeconômicos, os quais preencheram um Inventário de Recursos do Ambiente Familiar (RAF) e um Questionário sobre as necessidades das famílias (QNF).

Com base na pesquisa, foi possível verificar que os familiares dessas crianças necessitavam de maiores informações sobre os serviços especializados e ações de apoio dos quais seus filhos poderiam beneficiar-se posteriormente, bem como de encontros regulares com pessoas adequadas (como profissionais de saúde e educação), para falar sobre a deficiência do filho, além de serviços de apoio social e educativo, além de auxílio para pagamento de despesas.

Christovam e Cia (2013), ao buscarem identificar a percepção de pais e professores de estudantes PAEE sobre a relação família e escola, aplicaram questionários a sessenta pais e cinquenta e quatro professores de um município de médio porte do interior paulista. Os dados mostraram que a troca de informações entre a família e escola foi apontada pelos participantes da pesquisa como um fator de influência no sucesso acadêmico dos estudantes PAEE.

Azevedo e colaboradores (2015), ao avaliarem a opinião de mães de crianças PAEE sobre um programa de intervenção, sinalizaram a importância deste para que as mães esclarecessem as dúvidas e atendessem de forma mais efetiva a necessidade das crianças. Entre os assuntos tratados no programa de intervenção, destacaram-se a importância da família para o desenvolvimento infantil, estimulação e o papel dos pais, relação família-escola e direitos das pessoas com deficiência.

Observando-se então os dados dos estudos apresentados (SMEHA; OLIVEIRA, 2014; ARAÚJO, 2011; GUALDA; BORGES; CIA, 2013; KLEBA; WENDAUSEN, 2009) compreende-se que o conhecimento sobre os direitos sociais e a participação da família na conquista desses direitos possibilita que os estudantes PAEE possam usufruir mais efetivamente do direito educacional (BRAGA; FEITOSA, 2016).

Considerando-se a ampla legislação brasileira que ratifica que os estudantes PAEE, de qualquer idade, não sejam excluídos do sistema educacional, em nenhum nível, sob alegação de deficiência, assim como que recebam o apoio necessário, torna-se fundamental a ampliação de espaços para que os familiares compartilhem suas angústias, dúvidas e sentimentos, além de se apropriarem dos dispositivos legais (BRAGA; FEITOSA, 2016; VINENTE; DUARTE, 2017). 
http://dx.doi.org/10.5902/1984686X39311

Ao relacionarmos, então, os estudos desenvolvidos sobre a temática, verificamos que a maioria trata-se da relação entre familiares de estudantes público-alvo da Educação Especial e a escola, envolvimento parental e desenvolvimento de múltiplos programas de intervenção.

Referente aos serviços de AEE que são ofertados nas SRM, poucos estudos que exploram a percepção dos pais sobre esses serviços foram identificados. No contexto local de realização do presente estudo, não foi identificada nenhuma pesquisa sobre avaliação desse serviço a partir da ótica dos pais.

Ao observarmos que o momento atual é decisivo para a discussão e reformulação da PNEEP/EI ${ }^{1}$, tal estudo poderá contribuir para análise de um serviço educacional a partir da ótica dos familiares de estudantes PAEE, buscando elementos para compreensão de suas demandas e possíveis ajustes relacionados ao modus operandi de oferta dos serviços especializados.

Considerando os trabalhos sobre escolarização dos estudantes e a participação da família nesse processo pode-se realizar, então, o seguinte questionamento: quais as percepções dos familiares de estudantes PAEE sobre o Atendimento Educacional Especializado (AEE) ofertado nas Salas de Recursos Multifuncionais (SRM)?

Dessa forma, o estudo apresenta como objetivos descrever e analisar as percepções dos familiares de estudantes público-alvo da Educação Especial sobre o serviço de Atendimento Educacional Especializado ofertado em um município amazonense de grande porte.

\section{Método}

\section{Delineamento}

O estudo possui delineamento descritivo, por abordar descrição, registro, análise e interpretação de fenômenos atuais, objetivando o seu funcionamento no futuro (MARCONI; LAKATOS, 2015).

\section{Aspectos Éticos}

O projeto foi submetido ao Comitê de Ética em Pesquisa com Seres Humanos da Universidade Federal de São Carlos (UFSCar), atendendo as Resoluções do Conselho Nacional de Saúde oํ 466/2012 e no 510/2016, visando o desenvolvimento da pesquisa dentro dos padrões éticos (BRASIL, 2012, 2016). 
http://dx.doi.org/10.5902/1984686X39311

O Certificado de Apresentação para Apreciação Ética (CAAE) encontra-se cadastrado na Plataforma Brasil sob o código n` 96937118.4.0000.5504. Os participantes do estudo foram informados quanto aos objetivos, benefícios e riscos da pesquisa, assinaram o Termo de Consentimento Livre e Esclarecido (TCLE) e receberam uma via do Termo.

\section{Participantes}

Participaram do estudo cinco (05) familiares de estudantes público-alvo da educação especial, dos gêneros masculino e feminino, os quais foram selecionados por amostragem de conveniência, recrutados no ambiente escolar, após reunião com o gestor escolar.

Como critérios de inclusão, os participantes deveriam possuir em seu contexto familiar estudantes público-alvo da Educação Especial matriculados na escola investigada; e aceitar participar do estudo de forma voluntária. O perfil dos participantes pode ser observado no Quadro 1, a seguir:

Quadro 1 - Perfil dos participantes do estudo

\begin{tabular}{|c|c|c|c|}
\hline Participante & Parentesco & Idade & Escolaridade \\
\hline P1 & Mãe & 36 & Ensino Médio incompleto \\
\hline P2 & Mãe & 35 & Ensino Médio incompleto \\
\hline P3 & Mãe & 31 & Ensino Médio completo \\
\hline P4 & Pai & 30 & Ensino Superior completo \\
\hline P5 & Mãe & 35 & Ensino Médio completo \\
\hline
\end{tabular}

Fonte: Elaboração própria com base nos dados do estudo (2019).

Conforme observado no Quadro 1, dos participantes que integraram a investigação, P1, P2, P3 e P5 são do gênero feminino e apenas P4 do gênero masculino.

Os dados apontaram também que os familiares responsáveis pelos estudantes matriculados nos serviços especializados possuíam renda mensal entre um salário mínimo da época da realização do estudo $(R \$ 998,00)$ e $R \$ 1.700,00$.

Quanto à escolaridade, P1 e P2 possuíam Ensino Médio incompleto; P3 e P5 Ensino Médio completo e apenas P4 possuía Ensino Superior. A partir desse perfil pode-se potencializar efetiva análise no item resultados e discussões, o qual será apresentado posteriormente. 
http://dx.doi.org/10.5902/1984686X39311

\section{Local}

Os dados do estudo foram coletados nas dependências de uma escola da rede pública municipal de ensino, situada na zona norte de um município amazonense de grande porte. Dados do Instituto Brasileiro de Geografia e Estatística (IBGE) situam o município em questão, como o sétimo mais populoso do Brasil, com uma população estimada em 2.130.264 habitantes, distribuída em uma área de unidade territorial de $11.401,092$ km². (IBGE, 2019).

A rede pública municipal de ensino conta com aproximadamente 481 escolas, das quais 397 estão situadas na zona urbana e 84 localizam-se na zona rural do município (VINENTE, 2017). Embora o quantitativo de escolas seja razoável para o atendimento educacional da população em fase de escolarização, o número de Salas de Recursos Multifuncionais disponíveis na rede é de apenas 46, sendo considerado então insuficiente para a oferta dos serviços de AEE (SANTOS, et. al., 2017; VINENTE; OLIVEIRA, 2017).

\section{Instrumento}

O instrumento da pesquisa baseou-se na confecção de um roteiro semiestruturado de entrevista, constituído por 23 questões abertas e 04 questões fechadas, compreendendo temas como: encaminhamento de estudantes público-alvo da Educação Especial às SRM; percepção sobre o serviço de AEE; e a participação da família no acompanhamento do serviço de AEE.

Sobre o encaminhamento dos estudantes PAEE aos serviços especializados 0 questionário abordou o motivo dos pais pela opção de matrícula na escola; sobre o turno do serviço prestado; sobre o próprio processo de matrícula, entre outras coisas.

Sobre a percepção do serviço de AEE o questionário contou com questões sobre percepção dos pais sobre as atividades realizadas pelo professor do serviço; possíveis benefícios do serviço para o estudante; nível de satisfação dos pais em relação aos serviços, entre outras informações.

\section{Procedimentos de coleta dos dados}

Considerando que um instrumento de pesquisa precisa apresentar elementos como fidedignidade e operatividade (MARCONI; LAKATOS, 2003), foi realizada uma testagem do roteiro semiestruturado de entrevista. $O$ instrumento foi aplicado a dois familiares de 
estudantes com deficiência intelectual em uma escola da rede pública estadual de ensino do município investigado.

O contato preliminar com a escola se deu mediante apresentação de Ofício solicitando autorização para a realização da pesquisa no âmbito do estabelecimento de ensino. Após ter acesso ao projeto de pesquisa, o gestor escolar emitiu Carta de Autorização com a anuência, a qual foi submetida juntamente com outros documentos ao Comitê de Ética em Pesquisa com Seres Humanos (CEP) da Universidade Federal de São Carlos (UFSCar).

Posteriormente à aprovação do CEP/UFSCar, o pesquisador entrou em contato com o gestor escolar e realizou o recrutamento dos participantes por meio do envio de Carta Convite. Após o contato com os familiares, as entrevistas foram agendadas e realizadas no estabelecimento de ensino durante o período de oferta do AEE no contraturno.

A entrevista selecionada para ser aplicada aos familiares de estudantes PAEE foi a semiestruturada, por esta ser focalizada em um assunto sobre o qual confeccionamos um roteiro com perguntas principais, complementadas por outras questões inerentes às circunstâncias momentâneas à entrevista (FRASER; GONDIM, 2004). O roteiro foi baseado em um planejamento, de modo que pudesse responder aos objetivos da pesquisa, tendo sido tomados os cuidados para a elaboração, associados à linguagem, à forma das perguntas e à sequência das perguntas nos roteiros (MANZINI, 2004).

O roteiro foi aplicado durante a entrevista com os familiares em espaço cedido pelo gestor da escola, de modo que os familiares se sentissem confortáveis a responder as questões. A média de duração das entrevistas foi de aproximadamente quatorze (14) minutos, tendo sido a maior duração aproximada de vinte e três (23) minutos; e a menor, sete (7) minutos.

\section{Procedimentos de Análise dos Dados}

De acordo com Frigotto (2008, p. 89), "[...] é na análise que se estabelecem as relações entre a parte e a totalidade". Sendo assim, esse processo é essencial no estudo por representar o esforço de estabelecer conexões, mediações e contradições dos fatos que constituem a problemática pesquisada.

Os dados relacionados aos relatos dos familiares, obtidos por meio da entrevista semiestruturada, foram transcritos pelo pesquisador e um auxiliar de pesquisa, identificando-se os discursos que atendiam aos objetivos da pesquisa (MANZINI, 2004). 
Os relatos transcritos foram apreciados a partir de categorias temáticas, tendo participado dois juízes, com a finalidade de verificar a concordância dos dados obtidos. Cabe salientar que serão apresentados apenas dados parciais, de um estudo mais amplo, destacando-se as categorias temáticas preliminares que emergiram.

Os dados foram analisados a partir de sete categorias temáticas, a saber: (1) Perfil das crianças que frequentam os serviços especializados; (2) Importância dos serviços especializados na região; (3) Processo de matrícula na escola comum; (4) Percepção sobre as atividades realizadas no AEE; (5) Acompanhamento e monitoramento dos familiares frente aos serviços especializados.

\section{Resultados e discussão}

\section{Perfil das crianças que frequentam os serviços especializados}

Em relação às crianças que frequentavam os serviços especializados optou-se por denominá-las pela sigla C. Desse modo, com base nos dados, C1 e C5 possuíam seis anos, C2 e C3 possuíam sete anos respectivamente; e C4 10 anos. Dessa maneira, participaram dos serviços especializados tanto estudantes da Educação Infantil, quanto da primeira etapa do Ensino Fundamental.

É importante destacar que o Atendimento Educacional Especializado, segundo normativa do Decreto № 7.611/2011, é complementar à formação dos estudantes com deficiência e transtornos globais do desenvolvimento, bem como suplementar a formação de estudantes com altas habilidades ou superdotação (BRASIL, 2011).

Nessa perspectiva, em relação ao quadro clínico, disposto no processo de matrícula dos alunos, C1, C3, C4 e C5 possuíam laudo médico com o diagnóstico de autismo leve e apenas C2 com quadro clínico de hidrocefalia. Ou seja, esses estudantes frequentavam o AEE na modalidade de serviço complementar, previsto na legislação como apoio permanente e limitado no tempo e na frequência dos estudantes às salas de recursos multifuncionais (BRASIL, 2011).

Estudo semelhante de Salvini e colaboradores (2019) apontam que os serviços de AEE buscam auxiliar os estudantes PAEE no exercício de práticas educativas desenvolvidas na sala de aula regular. Visando estimar o impacto do Programa de Implantação de Salas de Recursos Multifuncionais sobre a defasagem escolar dos alunos que avançavam no processo de inclusão escolar, a partir dos microdados do Censo 
http://dx.doi.org/10.5902/1984686X39311

Escolar de 2016, os autores realizaram um estudo empírico utilizando o método Propensity Score Matching.

Quanto ao gênero, todas as crianças as quais os familiares participaram do estudo, são do gênero masculino. Embora os estudos de Salvini e colaboradores (2019) tenham evidenciado que os estudantes de raça branca demonstram maior probabilidade de acesso ao Programa, o determinante "cor" ou "raça" não foi objeto de análise dessa pesquisa. Todas as crianças residiam na zona urbana da cidade, morando próximas ao estabelecimento de ensino e frequentavam o serviço de AEE na Sala de Recursos Multifuncionais durante o contraturno. Nessa mesma perspectiva, sabe-se que a residência desses alunos em zona urbana possibilita aos estudantes maior acesso aos serviços, bem como a disponibilização de profissionais mais capacitados (SALVINI, et al, 2019)

O quantitativo de estudantes com autismo matriculados nos serviços especializados das salas de recursos multifuncionais aponta um crescimento em relação ao quantitativo de crianças com outras deficiências. O estudo de Vinente (2017) apontou que na rede pública do município, o número de crianças com autismo era inferior apenas ao quantitativo de estudantes com deficiência intelectual. Esse dado pode ser observado também em outros estudos (SILVA, 2010; SOUZA, 2011; CORRÊA, 2013; SEMKIV, 2015).

Em relação ao tempo de estudo na escola regular, C2, C3, C4 e C5 frequentavam o estabelecimento de ensino há quase dois anos; apenas C1 estava matriculado pelo primeiro ano. É importante destacar que, com base nos relatos dos familiares, o fato de a matrícula ter ocorrido na escola regular, nem sempre potencializou que os serviços especializados fossem ofertados desde o ingresso do estudante no estabelecimento de ensino.

\section{Importância dos serviços especializados na região}

O município alvo da realização desse estudo situa-se no centro da maior floresta equatorial do mundo, de clima tropical, bastante densa, úmida e com grande diversidade de espécies animais e vegetais. Importante também destacar a proximidade do município com a Linha do Equador e a influência no clima global por situar-se em uma área de grande floresta. 
Ao mesmo tempo em que verificamos a importância da região para o desenvolvimento regional pode-se verificar também a importância de uma educação atenta à diversidade humana tão presente. Essa diversidade além de permear os estudantes PAEE matriculados na região também volta para as populações indígenas, os ribeirinhos e as populações quilombolas inseridas nesse grande espectro sócio cultural.

Assim sendo, ao considerarmos então a concretização do acesso e a permanência dos estudantes PAEE no ensino regular verifica-se a democratização do acesso dessas populações ao AEE enquanto serviço gratuito, ofertado pelo Poder Público. Desta feita, o ingresso aos serviços de AEE pressupõe acesso a um conjunto de atividades, recursos de acessibilidade e pedagógicos organizados institucional e continuamente (BRASIL, 2011).

Sendo assim, tais serviços devem ser prestados de modo que contribuam com o processo de inclusão escolar desses estudantes. Dados do estudo de Salvini e colaboradores (2019) apontam que o fato de os alunos estarem matriculados em escola pública e terem acesso ao transporte escolar afetam positivamente a probabilidade de participação no AEE. Além disso, sabe-se que a ampliação das políticas de promoção desse atendimento tem oportunizado, nos últimos anos, maior inserção desse alunado nos sistemas de ensino (BAPTISTA, 2011; MENDES; CIA, 2012; NOZU, 2013; SALVINI, et al, 2019).

Quanto aos aspectos de gênero e sócio econômicos dos participantes, conforme observado no Quadro 1, quatro (4) eram do gênero feminino e um (1) do gênero masculino. Esses familiares possuíam renda mensal entre um salário mínimo e mil e setecentos reais, em um contexto familiar de aproximadamente quatro pessoas em um domicílio.

Quanto à escolaridade, P1 e P2 possuíam Ensino Médio incompleto; P3 e P5 Ensino Médio completo e apenas P4 possuía Ensino Superior. O conjunto habitacional no qual residiam também possuía requisitos para habitação dessas famílias, dos quais podem-se elencar: (a) famílias que residiam na condição de cedidos ou alugados; (b) famílias que não foram contempladas com programas habitacionais de esfera federal, estadual, municipal, bem como assentamentos; (c) famílias com membros que possuíam doenças crônicas degenerativas; (d) famílias chefiadas por mulheres; e (e) famílias residentes em áreas de risco. 
O acesso aos programas sociais tem também evidenciado ampliação da escolarização dos estudantes, sejam alunado da Educação Especial ou não, no entanto, os grupos beneficiários dos programas de transferência de renda enfrentam condições adversas que limitam sua inserção e emancipação social. Tais condições envolvem baixas escolaridade e qualificação para o trabalho; trabalho informal e mal remunerado; serviços ainda insuficientes de abastecimento e tratamento da água, além de esgotamento sanitário e coleta de lixo (OLIVEIRA, 2009; MAGALHÃES, et al, 2013).

Considerando então a relevância dos serviços de $A E E$ prestados à população dessa zona do município evidencia-se que o maior acesso à escolarização pode beneficiar esses estudantes com maiores chances de empregabilidade e qualificação profissional.

Precisa-se enfatizar também que, como afirmam Kleba e Wendausen (2009, p. 741), recursos estruturais favorecem a melhoria da qualidade de vida. Assim, esses recursos "promovem experiência subjetiva de segurança, capacidade de intervenção e reconhecimento social dos indivíduos e das famílias". Como recursos estruturais podem ser citados o capital econômico (renda, habitação, acesso a bens de consumo) e o capital cultural (conhecimento/informação, capacidade de reflexão e análise sobre a realidade, formação e identidade profissional).

\section{Processo de matrícula na escola comum}

O direito à matrícula dos estudantes PAEE no sistema regular de ensino ampara-se na legislação brasileira, que traz, por exemplo, no atual Plano Nacional de Educação (PNE), a universalização para os estudantes dos quatro (4) aos dezessete (17) anos "[...] o acesso à educação básica e ao atendimento educacional especializado, preferencialmente na rede regular de ensino, com a garantia de sistema educacional inclusivo, de salas de recursos multifuncionais, classes, escolas ou serviços especializados, públicos ou conveniados" (BRASIL, 2014b, n.p.).

$\mathrm{O}$ instrumento de pesquisa continha aproximadamente três questões relacionadas ao processo de matrícula do estudante na escola comum. Vale destacar que apenas $\mathrm{C} 1$, C2 e C5 estavam matriculados na mesma escola que oferta o serviço de Atendimento Educacional Especializado na Sala de Recursos Multifuncionais. Já C3 e C4 foram matriculados em uma escola próxima, porém frequentavam o serviço durante 0 contraturno em outra escola no mesmo bairro. 
http://dx.doi.org/10.5902/1984686X39311

Questionados sobre o motivo de terem matriculado os estudantes na escola em que eles frequentavam, os participantes apresentaram motivos variados, como pode ser observado no Quadro a seguir:

Quadro 2 - Motivo de matrícula dos estudantes na escola comum

\begin{tabular}{|c|l|}
\hline Participante & \multicolumn{1}{|c|}{ Motivo pela opção de matrícula na escola } \\
\hline $\mathbf{P 1}$ & $\begin{array}{l}\text { Proximidade da casa com a escola, pelo fato de ter uma criança com } \\
\text { deficiência. }\end{array}$ \\
\hline $\mathbf{P 2}$ & $\begin{array}{l}\text { Não houve opção pela matrícula. A criança foi encaminhando pelo Complexo } \\
\text { Municipal de Educação Especial }\end{array}$ \\
\hline $\mathbf{P 3}$ & $\begin{array}{l}\text { Proximidade da casa com a escola e indicação de familiares de outras crianças } \\
\text { relacionada aos serviços especializados. }\end{array}$ \\
\hline $\mathbf{P 4}$ & $\begin{array}{l}\text { Proximidade da casa com a escola, pois a escola anterior era muito distante } \\
\text { do domicílio. }\end{array}$ \\
\hline $\mathbf{P 5}$ & $\begin{array}{l}\text { Proximidade da casa com a escola e o fato de a criança estudar lá desde a } \\
\text { Educação Infantil. }\end{array}$ \\
\hline
\end{tabular}

Fonte: Elaboração própria com base nos dados do estudo (2019).

Com base nos fragmentos de relatos apresentados no Quadro 2, foi possível verificar que a proximidade da escola em relação ao domicílio da criança é um dos principais motivos para a matrícula, como ocorreu com P1, P3, P4 e P5.

Além desse item, a indicação de familiares de outras crianças que já realizaram anteriormente a matrícula desses estudantes auxilia na escolha. Como no estudo de Corrêa (2013), a sala de recursos multifuncionais atendia ao estudante no turno oposto, podendo esse atendimento ser realizado tanto na própria escola do aluno, se esta possuísse SRM ou na escola que apresentasse a sala mais próxima de sua casa.

Outro ponto levantado pelos relatos dos familiares diz respeito ao encaminhamento do estudante pelo Complexo Municipal de Educação Especial, o qual definiu que a matrícula ocorreria no estabelecimento de ensino. Estudos anteriores têm apontado que a identificação, avaliação e encaminhamento dos estudantes público-alvo da Educação Especial aos serviços especializados ocorreram com ampla atuação desse Complexo (MATOS, 2008, MARQUES, 2010; VINENTE, 2017; SANTOS, et al, 2017; GALVANI; VINENTE, 2020).

Outro dado importante diz respeito ao processo de matrícula dos estudantes públicoalvo da Educação Especial na rede pública municipal de ensino. P1 não relatou incidentes durante o processo de matrícula. No entanto, P2 relatou que foi necessário buscar no 
http://dx.doi.org/10.5902/1984686X39311

Complexo Municipal de Educação Especial um encaminhamento para a matrícula, para a vaga ser deferida pelo estabelecimento de ensino.

O participante P3 relatou ter dormido na fila para assegurar a vaga do filho. Questionado sobre conhecer a prioridade na matrícula, P3 afirmou desconhecer o direito à prioridade na matrícula e alegou que muitas mães faziam da mesma forma. Já P4 enfatizou a necessidade de se dirigir ao Complexo e aguardar uma lista de espera para a obtenção da vaga para o familiar.

P5 argumentou que o processo de matrícula foi rápido, entretanto, destacou que após o envio dos documentos, levou um tempo para a confirmação da vaga. Além disso, P5 informou que a oferta do serviço de AEE iniciou-se apenas após a apresentação do laudo médico.

Semelhanças na forma como esse processo de identificação, avaliação e matrícula desses estudantes são encontrados em outros estudos (PRIETO; SOUSA, 2007; SILVA, 2010; PLETSCH, 2012; SEMKIV, 2015; VINENTE, 2017).

Sobre a necessidade do laudo médico para a prestação dos serviços especializados aos estudantes PAEE, a Nota Técnica ํㅜ 04/2014/MEC/SECADI/DPEE orientou quanto aos documentos comprobatórios para registro no Censo Escolar. Dessa forma, segundo orientação oficial:

[...] não se pode considerar imprescindível a apresentação de laudo médico (diagnóstico clínico) por parte do aluno com deficiência, transtornos globais do desenvolvimento ou altas habilidades/superdotação, uma vez que o AEE caracteriza-se por atendimento pedagógico e não clínico (BRASIL, 2014b, p. 3)

Ao se considerar então a orientação da Nota Técnica, o processo de matrícula no AEE e o cadastro do estudante no Censo Escolar não dependem de apresentação do laudo médico. Assim, não é justificável a triagem dessas crianças e o aguardo da emissão desse documento para a realização da matrícula. A legislação garante ser necessário apenas o Plano de AEE elaborado pelo professor da sala de recursos multifuncionais (BRASIL, 2010).

A legislação do município também estabelece, por meio da Resolução no 011/CME/2016, que as instituições mantidas pelo Poder Público deverão realizar chamada pública para matrícula antecipada dos estudantes PAEE (MANAUS, 2016).

Sendo assim, não haveria necessidade de P3 dormir na fila para assegurar matrícula de seu filho, considerando que a educação é direito público subjetivo, assegurado em ampla 
http://dx.doi.org/10.5902/1984686X39311

legislação (BRASIL, 1988, 1996, 2011, 2015). Além dessa prerrogativa, a legislação municipal assegura que, independente do período reservado no calendário escolar, a matrícula pode ocorrer a qualquer tempo do período letivo.

Em relação à exigência da documentação para matrícula nos serviços especializados, a legislação municipal elenca o laudo médico, a avaliação multiprofissional e o relatório do professor do AEE como documentos comprobatórios de deficiência. No entanto, "[...] o laudo médico é documento obrigatório para efeito de registro escolar, devendo ser apresentado como documento complementar" (MANAUS, 2016, p. 8), contrariando a normativa nacional (BRASIL, 2014b).

\section{Percepção sobre as atividades realizadas no Atendimento Educacional Especializado}

Quando questionados se conheciam as atividades realizadas pela professora da Sala de Recursos Multifuncionais, os familiares afirmaram conhecer parte delas. Entre as atividades mais difundidas, a percepção dos familiares é de que a professora: (a) realiza atividades de pintura; (b) realiza atividades de encaixe; (c) realiza atividades lúdicas com os estudantes; (d) realiza atividades de leitura, escrita e aritmética; (e) confecção de brinquedos com recursos de baixo custo, dentre outras.

Verificou-se, com base no discurso dos participantes, que era comum o registro das atividades realizadas pelos alunos e o envio dessas imagens por meio de aplicativos de mensagens instantâneas. Nessa perspectiva, observa-se uma preocupação da professora do AEE em comunicar aos pais quanto a um feedback das atividades realizadas durante 0 período de oferta do AEE.

Como bem ilustram Pinto e Amaral (2019, p. 4):

As discussões sobre possibilidades e desafios da atuação docente perante
uma educação escolar que favoreça a aprendizagem e o desenvolvimento
dos alunos com deficiência, no âmbito da escola comum, precisam dar
visibilidade às interações com o outro e à construção de significados e
sentidos em torno das práticas pedagógicas. Para tanto, é importante
considerar contextos sociais mais amplos e concepções de ensinar e
aprender que embasem práticas pedagógicas desenvolvidas pelos
professores, bem como o papel central da escola no desenvolvimento dos
educandos.

Nessa perspectiva, a formação docente pode muito contribuir para as proposições de práticas pedagógicas exitosas junto aos estudantes PAEE. Corroborando Pinto e Amaral, Salvini (et al, 2019) descreve em seu estudo que o impacto negativo e significativo do acesso ao AEE sobre os anos de defasagem escolar para grande parte dos alunos PAEE. 
Assim, o AEE pode atuar como ferramenta de suporte, proporcionando a esses alunos maior nível de aprendizagem (SALVINI, et al, 2019).

Ao serem questionados se as crianças gostavam de frequentar os serviços do $A E E$ nas salas de recursos multifuncionais, os familiares foram unânimes em afirmar que elas possuíam amplo interesse em frequentar a Sala de Recursos Multifuncionais. Como pode ser observado nos trechos a seguir:

Demais. Ele ama a sala. (P1, 2019)

Ele gosta. Quando ele não vai, fica triste. Ele gosta de ir. Ele gosta do aprendizado. Ele gosta muito da professora. Acho que ele faz várias coisas na sala de recursos. Ela o ensina, pois já está escrevendo o nome dele. (P2, 2019)

Gosta, isso eu te garanto que ele gosta. (P3, 2019)

Adora. Adora. (P4, 2019)

Sim, ele gosta. Faz questão de ir [...] Duas vezes pra mim tá ótimo, porque fica muito puxado pra ele. (P5, 2019)

No trecho da fala de P1 é possível verificar o quanto a criança gosta de participar das atividades desenvolvidas na SRM. A mesma informação consta nos discursos dos participantes P2, P3, P4 e P5. A interlocução entre o ambiente da SRM com a motivação dos estudantes durante o período em que a frequentam contribui de forma significativa no processo de ensino e aprendizagem destas crianças.

Carvalho (2000) evidencia que, de certo modo, as escolas têm contado com a contribuição acadêmica da família de duas maneiras: (a) construindo o currículo (e o sucesso escolar) implicitamente com base no capital cultural similar dos alunos, o que supõe afinidade cultural entre escola e família. Assim sendo, a percepção dos familiares na compreensão da SRM enquanto espaço privilegiado na oferta do AEE possibilita uma avaliação positiva desse serviço.

Como apresentado na fala de P5, o tempo de duração da oferta do serviço de AEE duas vezes na semana parece positiva na ótica dos familiares. Uma das diretrizes desse atendimento, segundo o decreto regulamentador do AEE é a "adoção de medidas de apoio individualizadas e efetivas, em ambientes que maximizem o desenvolvimento acadêmico e social, de acordo com a meta de inclusão plena" (BRASIL, 2011, n.p.).

Ao considerarmos, então, o interesse das crianças em participar do AEE e a quantidade de dias em que frequentavam esse atendimento no contraturno, pode-se 
http://dx.doi.org/10.5902/1984686X39311

verificar aspectos da organização desse serviço. Dessa forma, dois dias são suficientes para o desenvolvimento de atividades suplementares ou complementares ao ensino?

Deve-se ressaltar que a busca pela inclusão desses estudantes no ambiente de ensino regular pode trazer benefícios não somente para o aluno incluído, mas pode promover também o amadurecimento e o desenvolvimento dos estudantes que não compõe o PAEE (BATISTA; ENUMO, 2004).

Isto posto, vê-se a urgência na constante reformulação das políticas voltadas aos estudantes da educação especial, para adequá-las às necessidades específicas desses alunos, proporcionando melhoras no desempenho escolar de todos os estudantes envolvidos (SALVINI, et al, 2019).

\section{Acompanhamento e monitoramento dos familiares frente aos serviços especializados}

Conforme observado no Quadro 1, dos participantes que integraram a investigação, P1, P2, P3 e P5 são do gênero feminino e apenas P4 do gênero masculino. Trazer essa questão de gênero presente no estudo coaduna com o que diz Carvalho (2000, p. 152), ao enfatizar que "é importante chamar a atenção para o alcance da política escolar sobre a família e especialmente sobre as mães, explicitando de que forma ela articula implicitamente escola e família como instâncias educativas".

Nesse sentido, mães acabam se desdobrando mais em suas atividades laborais e de convívio social para o acompanhamento das atividades escolares, as quais seus filhos participam. A implementação da política de educação especial traz possibilidades de intervenção que promovam mudanças significativas na relação família-escola, bem como na implementação dessa política.

Em relação ao acompanhamento e monitoramento dos familiares frente aos serviços especializados prestados na sala de recursos multifuncionais, os familiares foram questionados se possuíam o costume de se reunir com a professora do AEE. Todos os familiares afirmaram participar de reuniões curtas com a professora, incluindo o período de entrada e saída dos estudantes na escola.

Com base nos relatos dos familiares se pode notar que há uma interação entre a professora e os pais das crianças não apenas no âmbito da escola, mas fora dela por meio de aplicativos de comunicação e redes sociais. No entanto é importante discutir as funcionalidades da utilização desses instrumentos de comunicação, de modo que o horário 
http://dx.doi.org/10.5902/1984686X39311

do professor seja respeitado para a realização do planejamento de ensino e a avaliação dos demais estudantes.

Quando questionados sobre o nível de satisfação quanto ao serviço ofertado na sala de recursos multifuncionais, os participantes da pesquisa mostraram-se satisfeitos, como pode ser observado nos relatos.

É muito satisfatório. Eu gosto muito. [...] Assim, é como eu te falei, não pela $\mathrm{Neiva}^{2}$. Mas pelo espaço. Precisaria de mais um espaço para trabalhar com ele, essas coisas assim. (P1, 2019)

Até agora eu não tive nenhum problema não. Acho muito importante. Eu acho bom. Por mim, tudo bem! (P2, 2019)

Em termo dos professores eu acho maravilhoso. Em termo de aprimorar mais, melhorar a sala para o profissional trabalhar. Mas, o profissional em si não, eu estou bem satisfeita. (P3, 2019)

Acho a sala de recursos dez. Excelente! [...] Na questão do ensino regular que precisa melhorar. Pois não tem monitor. Meu filho tem muito suporte lá na sala de recursos. (P4, 2019)

É dez! É ótimo [...] Eu acho que poderia melhorar a questão da idade das crianças ou os graus. Tem crianças muito diferenciadas umas das outras [...] Por exemplo, o meu filho tem seis anos, ele é pequenininho. $E$ às vezes tem uns que são bem maiores que ele. Tem vezes que fica só ele de pequenininho e muitos grandes. Aí eu sinto uma diferença que é ruim. Essa questão de separação por idade, por transtorno, seria bacana. Eu tenho essa sugestão. (P5, 2019)

Conforme pode ser observado no relato de P1, o espaço da sala de recursos multifuncionais mostrou-se insuficiente para a realização das inúmeras atividades do AEE. Tal realidade se torna presente em vários estudos realizados em diversas regiões do país (BAPTISTA, 2011; MENDES; CIA, 2012; NOZU, 2013; ALBUQUERQUE, 2015; VINENTE, 2017).

Nesse cenário, conforme Nota Técnica nำ11/2010 - SEESP/GAB, o estabelecimento de ensino deve prever a "existência de espaço físico adequado para a sala de recursos multifuncionais; de mobiliários, equipamentos, materiais didático-pedagógicos e outros recursos específicos para o AEE, atendendo as condições de acessibilidade" (BRASIL, 2010, p. 3).

Sendo assim, P3 também chamou atenção para a questão da melhoria da sala, de modo que o professor do AEE possa desenvolver melhor o trabalho pedagógico com esses estudantes. Outra questão, levantada por P5, imprescindível para a melhoria dos serviços especializados ofertado na sala de recursos multifuncionais, diz respeito à forma de organização dos atendimentos pedagógicos aos estudantes. 
http://dx.doi.org/10.5902/1984686X39311

Para a participante, uma divisão das atividades a serem realizadas na SRM por tipos de deficiência e faixa etária poderia potencializar o atendimento ofertado, fator também apontado em alguns outros estudos (CORRÊA, 2013; GUALDA; BORGES; CIA, 2013; ALMEIDA, 2013; ALBUQUERQUE, 2015).

Em relação à percepção dos familiares quanto ao processo de inclusão escolar dos estudantes, os mesmos relataram diferentes olhares sobre o tema. Quando questionados se os estudantes gostavam de frequentar o espaço dos serviços de AEE constatamos as seguintes colocações, como pode ser observado a seguir:

Sim. Acredito que sim (P1, 2019).

Sim, eu acho que ele está aprendendo. Na sala de recursos ele planta. Isso ajuda. Ele faz muita coisa na sala de recursos. Isso ajuda a incluir ele, ajuda na participação dele (P2, 2019).

Olha! Eu vou te ser bem sincera. Não chega nem a sessenta por cento [...] A minha questão é o professor que meu filho pegou esse ano [...] (P3, 2019).

Não, se encontra totalmente não. Porque é como se ele tivesse lá não seguindo o conteúdo da turma. [...] Assim, respeitam ele e tal. Mas eu não sei. Só vou pegar ele no final da aula e ele não fala o que acontece lá. [...] (P4, 2019).

Sim, bastante, demais! A professora sente falta dele quando ele não está na sala de aula, quando ela faz atividades em grupo.

Ela faz questão que ele fale, interaja. Pra mim ele está indo muito bem. [...] (P5, 2019).

A partir dos relatos dos familiares podem-se observar aspectos favoráveis da participação desses estudantes na escola comum, com suporte do atendimento educacional especializado. Nessa perspectiva, P1 e P2 acreditavam que as crianças estivessem participando do processo de inclusão escolar.

P3, ao fazer observações sobre o professor da escola regular de seu filho, destaca que esse é um dos obstáculos para a efetivação do processo de inclusão escolar, fragmento esse que corrobora com o relato de P4. Já, o participante P5 destacou o papel do professor do ensino regular em consonância com a atuação da professora da sala de recursos multifuncionais.

Apesar dos apontamentos da literatura sobre os inúmeros problemas enfrentados (MENDES; CIA, 2012; BAQUERO, 2012; NOZU, 2013; ALBUQUERQUE, 2015), tanto pelos estudantes, como pelos profissionais da educação especial, acredita-se que a escola 
http://dx.doi.org/10.5902/1984686X39311

inclusiva é, de fato, a melhor alternativa para um ambiente de convívio social mais inclusivo, com iguais oportunidades para todos (SALVINI, et al, 2019).

Sabe-se que para o fortalecimento do ideário de inclusão escolar, uma boa formação docente e articulação do ensino comum com o AEE são aspectos indispensáveis. Dessa maneira, o envolvimento dos pais com a escola não beneficia apenas as crianças, pois as instituições que encorajam os familiares a participarem dos assuntos da escolarização de seus filhos tendem a fortalecer a comunidade como um todo (MARINS, CIA, 2019).

\section{Considerações finais}

O presente estudo teve com objetivo descrever e analisar as percepções dos familiares de estudantes PAEE sobre o serviço de Atendimento Educacional Especializado ofertado em um município amazonense de grande porte.

Os familiares que participaram do estudo eram responsáveis legais por crianças da Educação Infantil e dos primeiros anos do Ensino Fundamental. É importante destacar que uma dessas etapas da Educação Básica, o Ensino Fundamental, é uma das que possuem maiores índices de matrículas de estudantes PAEE.

Em relação ao tempo de permanência dos estudantes na escola regular variou entre um e dois anos. Isso também se torna um fator que limita a possibilidade de avaliação dos serviços especializados, os quais esses estudantes frequentavam.

Além disso, também se verificou que o fato de a matrícula ter ocorrido na escola regular, nem sempre potencializou que os serviços especializados fossem ofertados desde o ingresso do estudante no estabelecimento de ensino.

Outro dado relevante apresentado pelo estudo mostra a importância do atendimento individualizado ou em menor quantidade de estudantes, como o realizado na SRM. Essa proposta de serviço foi bem avaliada pelos participantes do estudo, se comparado às atividades realizadas pelas professoras do ensino regular.

Quanto à importância dos serviços especializados na região acredita-se que a participação desses estudantes nas atividades das salas de recursos multifuncionais contribui para a melhoria do desempenho acadêmico na escola. Segundo a percepção dos pais, o serviço possibilita o acesso ao direito do AEE, previsto no ordenamento jurídico brasileiro (BRASIL, 1988, 2011).

Entretanto, para se ter mais dados sobre avaliação da política de inclusão escolar, principalmente dos serviços ofertados nas Salas de Recursos Multifuncionais, tornam-se 
http://dx.doi.org/10.5902/1984686X39311

necessários mais estudos que envolvam uma amostragem mais ampla. Bem como dados sobre a percepção dos professores do ensino regular e do AEE sobre a participação dos familiares nesse processo.

Os familiares também relataram conhecer as atividades realizadas pela professora da Sala de Recursos Multifuncionais, as quais se baseavam em: (a) atividades de pintura; (b) atividades de encaixe; (c) atividades lúdicas com os estudantes; (d) atividades de leitura, escrita e aritmética; (e) confecção de brinquedos com recursos de baixo custo, dentre outras.

Por meio do estudo foi possível identificar o perfil dos familiares, escolaridade e renda mensal. No entanto, a pouca amostra não nos permite mensurar o perfil socioeconômico das famílias dos estudantes que frequentam os serviços especializados no município. Nessa perspectiva, há um campo profícuo a ser investigado relacionando principalmente essas variáveis ao empoderamento desses familiares.

Além disso, mapear os familiares que dependem economicamente dos programas de transferência de renda e as implicações dessas políticas juntamente com o Programa de Implantação de Salas de Recursos Multifuncionais pode contribuir para análise intersetorial de políticas educacionais e de assistência social.

Sabe-se que o sucesso escolar tem dependido do apoio direto e sistemático da família que investe nos filhos, compensando tanto dificuldades individuais quanto deficiências escolares. Sendo assim, o estudo evidenciou a participação dos familiares nos serviços e a importância destes no processo de implementação e avaliação da política de inclusão escolar.

Assim sendo, torna-se imprescindível que a escola utilize instrumentos para que os usuários desse serviço (familiares e estudantes) possam avaliar o serviço do AEE em salas de recursos multifuncionais. Tais instrumentos a serem implementados podem variar desde uma simples pesquisa de opinião sobre os serviços ofertados, bem como outros instrumentos utilizados para esses fins.

As contribuições do presente estudo para o avanço da área baseiam-se nos seguintes itens: (1) necessidade de estudos na região sobre avaliação da política de inclusão escolar a partir da ótica dos familiares; (2) contribuições de uma análise local no tocante às política nacional e suas implicações para a realidade escolar; e (3) compreensão do processo de matrícula dos estudantes e encaminhamento destes aos serviços especializados. 
http://dx.doi.org/10.5902/1984686X39311

Além disso, seria o espaço da SRM o único espaço para a oferta efetiva do AEE? No caso de instituições especializadas, outros estudos poderiam trazer um panorama mais abrangente desse serviço, ofertado tanto nas SRM quanto em outros espaços previstos na legislação, nos quais também são computadas as duplas matrículas do Fundo de Manutenção e Desenvolvimento da Educação Básica e de Valorização dos Profissionais da Educação Básica (FUNDEB).

Ao considerarmos então a concretização do acesso e a permanência desses estudantes na escola regular, pode-se verificar a democratização do acesso dessas famílias ao AEE enquanto serviço gratuito, ofertado pelo Poder Público. Dessa forma, tornase necessário que tais serviços sejam mais bem prestados a essas famílias, de modo que contribua com o processo de inclusão escolar desses estudantes.

\section{Referências}

ALBUQUERQUE, E. R. Prática pedagógica inclusiva: um estudo de caso em escola com atendimento educacional especializado (AEE) em Jaboatão dos Guararapes - PE. 2014. 340f. Tese (Doutorado em Educação) - Universidade Federal de Pernambuco, Recife, 2015.

ALMEIDA, E. A. S. T. Atendimento educacional especializado e educação inclusiva: quais as experiências das salas de recursos multifuncionais nas escolas públicas de Niterói/RJ? 2013, 150f. Dissertação (Mestrado em Educação) - Faculdade de Educação, Universidade Federal Fluminense, Niterói, 2013.

\section{ARAÚJO, R. M. Empoderando pais para a luta pelos direitos de seus filhos com} deficiência: pesquisa-ação emancipatória. 187f. Tese (Doutorado em Educação Especial), Centro de Educação e Ciências Humanas, Universidade Federal de São Carlos, São Carlos, 2011.

AZEVEDO, T. L. et al. Avaliação das mães de crianças pequenas público-alvo da Educação Especial sobre um programa de intervenção. Revista Brasileira de Educação Especial, Marília, v. 21, n. 3, p. 377-394, 2015.

BAPTISTA, C. R. Ação pedagógica e Educação Especial: a sala de recursos como prioridade na oferta de serviços especializados. Revista Brasileira de Educação Especial, Marília, v. 17, p. 59-76, maio/ago. 2011.

BAQUERO, R. V. A. Empoderamento: instrumento de emancipação social? Uma discussão conceitual. Revista Debates, Porto Alegre, v. 6 (1), p. 173-187, jan./abril, 2012.

BATISTA, M. W.; ENUMO, S. R. F. Inclusão escolar e deficiência mental: análise da interação social entre companheiros. Estudos de Psicologia, Campinas, v. 9, n. 1, p. 101-111, 2004. 
BOARINI, M. L. Refletindo sobre a nova e a velha família. Psicologia em Estudo, Maringá, v. 8, n. esp., p. 1-2, 2003.

BRAGA, J. C. F.; FEITOSA, G. R. P. Direito à educação da pessoa com deficiência: transformações normativas e a expansão da inclusão no Brasil. Revista Direitos Humanos e Democracia, v. 4, n. 8, jul./dez. p. 310-370, 2016.

BRASIL. Constituição da República Federativa do Brasil, de 5 de outubro de 1988. Diário Oficial [da] República Federativa do Brasil, Brasília, DF, 5 out. 1988.

BRASIL. Decreto ํㅜ 7.611, de 17 de novembro de 2011: dispõe sobre a educação especial, o atendimento educacional especializado e dá outras providências. Diário Oficial [da] República Federativa do Brasil, Brasília, DF, 17 nov. 2011.

BRASIL. Lei n 13.005, de 25 de junho de 2014: aprova o Plano Nacional de Educação PNE e dá outras providências. Diário Oficial [da] República Federativa do Brasil, Brasília, DF, 25 jun. 2014a..

BRASIL. Lei no 13.146, de 6 de julho de 2015: Institui a Lei Brasileira de Inclusão da Pessoa com Deficiência (Estatuto da Pessoa com Deficiência). Diário Oficial [da] República Federativa do Brasil, Brasília, DF, 6 jun. 2015.

BRASIL. Lei no 8.069, de 13 de julho de 1990: dispõe sobre o Estatuto da Criança e do Adolescente e dá outras providências. Diário Oficial [da] República Federativa do Brasil, Brasília, DF, 13 jul. 1990.

BRASIL. Lei n 9.394, de 20 de dezembro de 1996: estabelece as diretrizes e bases da educação nacional. Diário Oficial [da] República Federativa do Brasil, Brasília, DF, 20 dez. 1996.

BRASIL. Supremo Tribunal Federal. Liminar Referendada: Decisão do Supremo Tribunal Federal, que por maioria, referendou a decisão liminar para suspender a eficácia do Decreto no 10.502/2020, nos termos do voto do Relator. Brasília, 21 dez. 2020.

BRASIL. Nota Técnica n 04/2014 MEC/SECADI/DPEE: Orientação quanto a documentos comprobatórios do cadastro de alunos com deficiência, transtornos globais do desenvolvimento e altas habilidades/superdotação no Censo Escolar. Brasília, DF, 23, jan. 2014b.

BRASIL. Nota Técnica no 11/2010 - SEESP/GAB: Orientações para a institucionalização da Oferta do Atendimento Educacional Especializado - AEE em Salas de Recursos Multifuncionais, implantadas nas escolas regulares. Brasília, DF, 7. Mai. 2010.

BRASIL. Política Nacional de Educação Especial na Perspectiva da Educação Inclusiva. Diário Oficial [da] República Federativa do Brasil, Brasília, DF, jan. 2008.

BRASIL. Portaria Normativa $n^{\circ}$ 13, de 24 de abril de 2007: dispõe sobre a criação do Programa de Implantação de Salas de Recursos Multifuncionais. Diário Oficial [da] República Federativa do Brasil, Brasília, DF, 24 abr. 2007. 
BRASIL. Resolução no 466, de 12 de dezembro de 2012: Diretrizes e normas regulamentadoras de pesquisas envolvendo seres humanos. Diário Oficial [da] República Federativa do Brasil, Brasília, DF, 12 dez. 2012.

BRASIL. Resolução no 510, de 6 de abril de 2016: Diretrizes e normas regulamentadoras de pesquisas envolvendo seres humanos. Diário Oficial [da] República Federativa do Brasil, Brasília, DF, 6 abr. 2016.

BRAVO, A. D; HAYASHI, M. C. P. I. As necessidades informacionais dos bacharéis em Direito na defesa das pessoas com necessidades especiais. Revista Eletrônica de Educação. São Carlos, v. 4, n. 1, p. 90-104, mai. 2010.

CARVALHO, M. E. P. Relações entre família e escola e suas implicações de gênero. Cadernos de Pesquisa, São Paulo, v. 110, p. 143-155, jul. 2003.

CHRISTOVAM, A. C. C.; CIA, F. O envolvimento parental na visão de pais e professores de alunos com necessidades educacionais especiais. Revista Brasileira de Educação Especial, Marília, v. 19, n. 4, p. 563-582, 2013.

CORRÊA, T. C. Avaliação, diagnóstico e encaminhamento de crianças com necessidades educacionais especiais no sistema municipal de ensino de LondrinaPR. 2013. 126f. Dissertação (Mestrado em Educação) - Universidade Estadual de Londrina, Londrina, 2013.

DUARTE, C. S. Direito público subjetivo e políticas educacionais. São Paulo em Perspectiva, São Paulo, v. 2, n. 18, p. 113-118. 2004.

FRASER, M. T. D.; GONDIM, S. M. G. Da fala do outro ao texto negociado: discussões sobre a entrevista na pesquisa qualitativa. Paidéia, Ribeirão Preto, v. 14, n. 28, p. 139152, 2004.

FRIGOTTO, G. O enfoque da dialética materialista histórica na pesquisa educacional. In: FAZENDA, I. (Org.). Metodologia da pesquisa educacional. 11. ed. São Paulo: Cortez, 2008. p. 69-90.

GALVANI, M. D.; VINENTE, S. Encaminhamento de estudantes com deficiência aos serviços de Educação Especial em Manaus: quais os critérios?. Ensino em Re-Vista, Uberlândia, v. 27, n. 2, p. 746-768, 2020.

GUALDA, D. S; BORGES, L.; CIA, F. Famílias de crianças com necessidades educacionais especiais: recursos e necessidades de apoio: recursos e necessidades de apoio. Revista Educação Especial, Santa Maria, v. 26, n. 46, maio./ago., p. 307-329, 2013.

HAAS, C. Ação pedagógica e inclusão escolar: uma análise sobre a função "complementar" do atendimento educacional especializado (AEE). Cadernos de Pesquisa em Educação, Vitória, n. 43, p. 88-104., 2016.

IBGE. Instituto Brasileiro de Geografia e Estatística. IBGE Cidades: Manaus. Disponível em: https://cidades.ibge.gov.br/brasil/am/manaus/panorama. Acesso em: 26 abr. 2019. 
KLEBA, M. E; WENDAUSEN, A. Empoderamento: processo de fortalecimento dos sujeitos nos espaços de participação social e democratização política. Saúde e Sociedade. São Paulo, v. 18, n. 4, p. 733-745, 2009.

MAGALHÃES, K. A. et al. A Habitação como Determinante Social da Saúde: percepções e condições de vida de famílias cadastradas no Programa Bolsa Família. Saúde e Sociedade. São Paulo, v.22, n.1, p.57-72, 2013.

MANAUS. Resolução no 011/CME/2016, de 02 de junho de 2016: Institui novos procedimentos e orientações para Educação Especial, na perspectiva da Educação Inclusiva, no Sistema Municipal de Ensino de Manaus. Diário Oficial do Município de Manaus. Manaus, AM, 02 jun. 2016.

MANZINI, E. J. Entrevista semi-estruturada: análise de objetivos e de roteiros. In: SEMINÁRIO INTERNACIONAL SOBRE PESQUISA E ESTUDOS QUALITATIVOS. 2004. Bauru. A pesquisa qualitativa em debate. Anais...Bauru: USC, 2004.

MARCONI, M. A.; LAKATOS, E. M. Técnicas de Pesquisa: planejamento e execução de pesquisas, amostragens e técnicas de pesquisa, elaboração, análise e interpretação de dados. 7. ed. São Paulo: Atlas, 2015.

MARCONI, M. A.; LAKATOS, E. M. Fundamentos de metodologia científica. 5. ed. São Paulo: Atlas, 2003.

MARINS, D. G.; CIA, F. O envolvimento entre família-escola de pré-escolares com deficiência, dificuldades escolares e desenvolvimento típico. RIAEE - Revista IberoAmericana de Estudos em Educação, Araraquara, v. 14, n. esp. 1, p. 883-899, abr., 2019.

MARQUES, M. P. S. D. O Acesso de Pessoas com Deficiência ao Sistema Público de Ensino de Manaus na Percepção dos Professores. 2010. 149f. Tese (Doutorado em Ciências: área Psicologia) - Faculdade de Filosofia, Ciências e Letras de Ribeirão Preto, Universidade de São Paulo, Ribeirão Preto, 2010.

MATOS, M. A. S. Cidadania, diversidade e educação inclusiva: um diálogo entre a teoria e a prática na rede municipal de Manaus. 2008. 229f. Tese (Doutorado em Educação) Faculdade de Educação, Universidade Federal do Rio Grande do Sul, Porto Alegre, 2008.

MATURANA, A. P. P. M.; CIA, F. Educação Especial e a Relação Família - Escola: Análise da produção científica de teses e dissertações. Psicologia Escolar e Educacional. Maringá, v. 19, n. 2, p. 349-358, maio/ago., 2015.

MENDES, E. G.; CIA, F. ONEESP - um Observatório Nacional para a comunidade da Educação Especial. In: MENDES, E. G.; ALMEIDA, M. A. (Org.). A pesquisa sobre inclusão escolar em suas múltiplas dimensões: teoria, política e formação. Marília: ABPEE, 2012.

MILANESI, J. B. Organização e funcionamento das salas de recursos multifuncionais em um município paulista. 2012. 183 f. Dissertação (Mestrado em Educação Especial) Centro de Educação e Ciências Humanas, Programa de Pós-Graduação em Educação Especial, Universidade Federal de São Carlos, São Carlos, 2012. 
NOZU, W. C. S. Política e gestão do atendimento educacional especializado nas salas de recursos multifuncionais de Paranaíba/MS: uma análise das práticas discursivas e não discursivas. 2013. 241f. Dissertação (Mestrado em Educação) Faculdade de Educação, Universidade Federal da Grande Dourados, Dourados, 2013.

OLIVEIRA, N. H. D. Recomeçar: família, filhos e desafios. São Paulo: UNESP, 2009.

OLIVEIRA, S. S. B. O programa Bolsa Familia na cidade de Manaus: análise das dimensões da inclusão social e escolar.158 f. 2009. Tese (Doutorado em Educação) Universidade Estadual de Campinas, Faculdade de Educação, Campinas, SP. 2009.

PLETSCH, M. D. Educação Especial e Inclusão Escolar: uma radiografia do atendimento educacional especializado nas redes de ensino da Baixada Fluminense/RJ, Ciências Humanas e Sociais em Revista, Rio de Janeiro, v. 34, n.12, jan / jun, p. 31-48, 2012.

PINTO, G. U.; AMARAL, M. H. Formação docente continuada e práticas de ensino no atendimento educacional especializado, Pro-posições, Campinas, v. 30, n. 2, 2019.

PRIETO, R. G. SOUSA, S. Z. L. Educação Especial: atendimentos em salas de recursos na rede municipal de São Paulo. Educação. Santa Maria, v. 32, n. 2, p. 375-396, 2007

SALVINI, R. R. et al. Avaliação do Impacto do Atendimento Educacional Especializado (AEE) sobre a Defasagem Escolar dos Alunos da Educação Especial. Estudos Econômicos, São Paulo, v. 49, n. Jul./Set. p. 539-568, 2019.

SANTOS, J. O. L. et al. Atendimento Educacional Especializado: reflexões sobre a demanda de alunos matriculados e a oferta de Salas de Recursos Multifuncionais na rede municipal de Manaus-AM. Revista Brasileira de Educação Especial, Marília, v. 23, n. 3, p. 409-422, jul./set., 2017.

SEMKIV, S. I. A. L. Análise da dinâmica de avaliação e encaminhamento de crianças com necessidades educacionais especiais num sistema municipal de ensino. 2015. 172f. Dissertação (Mestrado em Educação) - Universidade Estadual do Centro-Oeste, 2015. Guarapuava-PR, 2015.

SILVA, M. F. N. Encaminhamento de alunos para salas de recursos: análise sobre os argumentos apresentados por professores de classes comuns. 2010. 146f. Dissertação (Mestrado em Educação) - Faculdade de Educação, Universidade de São Paulo, São Paulo, 2010.

SILVEIRA, A. A. D. A busca pela efetividade do direito à educação: análise da atuação de uma Promotoria de Justiça da Infância e Juventude do interior paulista. Educação em Revista, Curitiba, n. especial 2, p. 233-250, 2010.

SMEHA, L. N, OLIVEIRA, V. L. P. Inclusão escolar: a perspectiva das mães de alunos com síndrome de Down. Revista Educação Especial. Santa Maria, v. 27, n. 49, p. 403416, mai./ago., 2014. 
http://dx.doi.org/10.5902/1984686X39311

SOUZA, P. M. Identificação e caracterização dos alunos com deficiência, transtornos globais do desenvolvimento e altas habilidades/superdotação, matriculados nas classes comuns do ensino regular, na rede pública estadual, em município do interior paulista. Dissertação (Mestrado em Ciências) - Faculdade de Filosofia, Ciências e Letras de Ribeirão Preto, Universidade de São Paulo, Ribeirão Preto, 2011.

VINENTE, S. Política e organização pedagógica do serviço de atendimento educacional especializado em Manaus. 2017. 176f. Dissertação (Mestrado em Educação Especial) - Universidade Federal de São Carlos, São Carlos, 2017.

VINENTE, S.; DUARTE, M. Percepção de familiares de pessoas com síndrome de Down sobre as políticas públicas. Revista Educação Especial em Debate, Vitória, v. 2, n. 4, p. 23-39, jul./dez., 2017.

VINENTE, S.; OLIVEIRA, S. S. B. Implementação do Atendimento Educacional Especializado e a formação de gestores na capital amazonense. Revista IberoAmericana de Estudos em Educação, Araraquara, v. 12, n. 1, jan./mar., p. 507-528, 2017.

\section{Notas}

1 Sobre esse tópico é importante destacar que ainda encontra-se vigente a Política Nacional de Educação Especial na Perspectiva da Educação Inclusiva (PNEEP/EI) publicada pela Ministério da Educação (BRASIL, 2008). Embora tenha sido realizada uma Consulta Pública em 2018 visando a reformulação desse documento, e posteriormente a publicação do Decreto oㅡ 10.502/2020, o mesmo foi considerado inconstitucional pelo Plenário do Supremo Tribunal Federal (STF) (BRASIL, 2020).

2 Optou-se pela utilização desse pseudônimo para resguardar a identidade dos participantes da pesquisa, conforme recomendações éticas de pesquisa com seres humanos (BRASIL, 2012). Embora Neiva não se trate de um familiar participante do estudo, refere-se ao nome de uma profissional da escola citada.

(c) (1) (9) International (CC BY-NC 4.0) 